Discussion Paper No. 15-076

The Impact of Administrative Transaction Costs in the EU Emissions Trading System

Peter Heindl

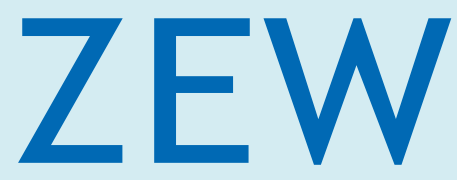

Zentrum für Europäische Wirtschaftsforschung $\mathrm{GmbH}$

Centre for European Economic Research 


\section{Discussion Paper No. 15-076 \\ The Impact of Administrative Transaction Costs in the EU Emissions Trading System}

Peter Heindl

Download this ZEW Discussion Paper from our ftp server:

http://ftp.zew.de/pub/zew-docs/dp/dp15076.pdf

Die Discussion Papers dienen einer möglichst schnellen Verbreitung von neueren Forschungsarbeiten des ZEW. Die Beiträge liegen in alleiniger Verantwortung der Autoren und stellen nicht notwendigerweise die Meinung des ZEW dar.

Discussion Papers are intended to make results of ZEW research promptly available to other economists in order to encourage discussion and suggestions for revisions. The authors are solely responsible for the contents which do not necessarily represent the opinion of the ZEW. 


\title{
The Impact of Administrative Transaction Costs in the EU Emissions Trading System
}

\author{
Peter Heindl \\ Centre for European Economic Research (ZEW) \\ L7, 1 \\ D-68161 Mannheim \\ Germany \\ heindl@zew.de \\ Phone: +49-621-1235-206 \\ Fax: +49-621-1235-226
}

October 2015

\begin{abstract}
This paper empirically investigates the impact of transaction costs for monitoring, reporting, and verification (MRV) of emissions on companies regulated by the EU Emissions Trading System (EU ETS) in Germany. Based on a unique panel dataset, we investigate if MRV costs are dependent on the amount of annual emissions of regulated companies and if there are differences in transaction costs between economic sectors. The results indicate that administrative costs are dependent on the amount of annual emissions for larger companies which has implications for the economic efficiency of the EU ETS. The most important finding, however, is that there are significant differences in MRV transaction costs dependent on the 'type' and 'size' of companies. This implies the existence of considerable economies of scale. Overall, the EU ETS could benefit from reforms by means of a push towards upstream regulation as this would likely increase administrative efficiency.
\end{abstract}

JEL-Classification: D22; D23; Q58

Keywords: EU Emissions Trading System; Cap-and-Trade; Transaction Costs; Monitoring, Reporting, and Verification

Acknowledgements: This research received funding from the Europeans Community's Seventh Framework Programme under Grant Agreement No. 308481. I thank Wolfgang Buchholz for helpful comments. 


\section{Introduction}

Transaction costs can decrease the economic efficiency of emissions trading systems substantially, especially if they cause irregular cost burdens among regulated companies. The attention for transaction costs in the EU Emissions Trading System (EU ETS) has increased in recent years. So far, the literature principally focuses on transaction costs for allowance trading, while the impact of administrative transaction costs is underexposed. Administrative costs occur as a result of mandatory compliance obligations, i.e. monitoring, reporting, and verification of annual emissions (MRV). Accurate reporting and a verification of emissions are indispensable for the proper functioning of emissions trading programmes or carbon taxes. Hence, administrative costs for MRV are to some degree unavoidable. Recognising the importance of accurate MRV for the proper functioning of systems, such as the EU ETS, the next question to ask is if administrative costs, among other things, should be regarded as an important issue for policy design. Thus, there is a trade-off between aspects of MRV transaction costs on the one hand and necessary MRV obligations on the other hand. Both aspects need to be considered for the design of emissions trading systems.

This paper investigates the impact of MRV transaction costs on the efficiency of the EU ETS empirically by using a unique set of administrative compliance data which are linked to firmlevel survey data. The effects of MRV transaction costs are relevant in two aspects, namely with respect to marginal transaction costs and with respect to average transaction costs. Non-zero marginal costs could cause disadvantages for the overall economic efficiency of the EU ETS since they would affect the output decisions of regulated companies (Mundaca, Mansoz, Neij, \& Timilsina, 2013). Substantial differences in average costs (e.g. as a result of high fixed transaction costs) would imply economies of scale in the MRV process and could cause high administrative costs per unit of emissions. In order to shed light on the question of whether or not MRV transaction costs should be regarded as an important issue in policy design within the scope of the EU ETS, we examine if there is empirical evidence for the existence of non-zero marginal costs or of substantial differences in average costs.

The European Commission has emphasised the importance of 'administrative efficiency' in the EU ETS and aims at reducing unnecessary administrative burdens for small emitters (directive 2009/29/EC, paragraph 11). However, there is still a lack of empirical evidence regarding this 
issue. The empirical assessment of administrative costs at the firm-level is a prerequisite for an informed policy debate and a possible future reform of the EU ETS (Joas \& Flachsland, 2014, Sec. 4.3). The insights gained from the EU ETS may also influence the design of (future) climate policy instruments other than the EU ETS. Two aspects are of particular interest in this case. Firstly, it is essential to examine whether administrative costs are dependent on the size of regulated companies or the amount of annual emissions of companies, and secondly, to investigate if costs differ between different types of firms or industrial installations. The latter aspect has received little attention in the literature so far.

This paper is organised as follows. A brief literature review is presented in Section 2. Section 3 provides a description of data, the empirical model specification, the identification strategy, and details on the proposed testable hypotheses. Estimation results are presented in Section 4. Section 5 concludes.

\section{The Literature}

Economic efficiency is of central interest to the design of economic instruments for climate protection. Although transaction costs are not the only aspects that have to be taken into account for policy design ${ }^{1}$, they are frequently discussed as an important source of excess costs under emissions trading with negative consequences for economic efficiency (Hahn \& Stavins, 2011). However, there is still a significant lack of empirical evidence regarding the extent of transaction costs and their relevance in practice.

Most of the literature on transaction costs in emissions trading revolves around the costs for trading of allowances. Stavins (1995) shows that transaction costs for allowance trading (e.g. trading fees) can reduce trading, and in doing so, increase overall costs and decrease economic efficiency . The initial distribution of allowances is relevant in this situation in so far that the 'independence property' is violated. ${ }^{2}$ Trading related transaction costs are seen as having

\footnotetext{
${ }^{1}$ Examples are the uncertainty of costs and the benefits of regulation (Hepburn, 2006) or political feasibility. The latter aspect has been of particular importance for policy choice and design in the European Union as coordination between member states and pre-existing regulations in some member states imposed a number of additional restrictions to policy choice and design (Ellerman, Convery, \& De Pertuis, 2010).

${ }^{2}$ Montgomery (1972) showed that the initial permit distribution will not be essential for the final outcome of regulation under cap-and-trade, and that overall control costs will be unaffected by the initial allocation. The allocation of allowances, thus, is an issue related to distributional aspects but does not affect cost efficiency. This is also called the 'independence property' (Hahn \& Stavins, 2011).
} 
potential adverse effects on economic efficiency in the EU ETS (Jaraitè-Kažukauskè \& Kažukauskas, 2014).

However, the term 'transaction costs' is used with respect to a wider range of costs other than transaction costs for allowance trading. The most relevant category in the EU ETS is the one related ex-post MRV transaction costs. While transaction costs for allowance trading solely occur in companies which actually trade (Jaraitė-Kažukauskė \& Kažukauskas, 2014), MRV transaction costs arise in every firm due to mandatory annual MRV obligations.

Merely a few contributions in literature focus on MRV costs in the EU ETS. Schleich and Betz (2004) point out that MRV costs for small and medium sized companies in the EU ETS could be large and should be evaluated carefully. Based on 27 interviews, Jaraite et al. (2010) show that the EU ETS has caused considerable MRV transaction costs in its implementation phase in Ireland in the period between 2005 and 2007, in particular for smaller firms or smaller emitters of carbon dioxide. With respect to MRV transaction costs, Jaraite et al. (2010, p. 198) report larger average costs per unit of emissions for small firms (1.51 EUR/tCO2) when compared to large firms (0.02 EUR/tCO2).

Joas and Flachsland (2014, Sec. 4.1) state that nonlinearities occur in MRV costs. Differences in MRV costs per unit of emissions between small and large emitters and the ratio between small and large entities under regulation are discussed as important aspects for policy design, i.e. when regulation should take place 'upstream' or 'downstream' (Joas \& Flachsland, 2014, Sec. 4.3). Kerr and Dusch (2015) consider transaction costs as part of an argument which is in favour of an upstream orientated regulation. Overall, MRV transaction costs are crucial with respect to the resulting total costs of firms caused by the EU ETS with consequences for ex-post allocation and efficiency (Mundaca et al., 2013, p. 494). ${ }^{3}$

Although research conducted by Ofei-Mensah and Bennett (2013) indicates that transaction costs for MRV activities are of great relevance for emissions trading programmes, the issue has received limited attention in the empirical literature on this topic so far (see also Mundaca et al., 2013, p. 502), partly due to a lack of data. This paper aims at filling this gap by empirically

\footnotetext{
3 One example is given by Kampas and White (2004). The authors showed that the optimal choice of taxation for the regulation of agricultural non-point source pollutants is dependent on administrative costs. When administrative costs are omitted, optimal policy design will differ as if administrative costs are included. A consistent emissions tax would be preferable in the former case, while a tax on inputs would be cost-minimising in the latter.
} 
investigating the extent of MRV transaction costs in the EU ETS. We examine the presence of non-zero marginal transaction costs in order to identify potential effects that MRV transaction costs might have on economic efficiency, as suggested by Mundaca et al. (2013) and Joas and Flachsland (2014). In addition to that, we investigate average transaction costs dependent on the firm-size and firm-type in Germany in order to allow for a detailed differentiation between various kinds of MRV transaction costs in the EU ETS. To our best knowledge, there is no detailed account with respect to the effects of 'firm-types' in relation to MRV transaction costs in literature so far.

\section{Data and Methods}

\subsection{Data Description}

The empirical analysis is based on two data sources. The amount of annual verified emissions, the information on free allocation, the number of EU ETS installations operated by firms, and the type of installation (i.e. if combustion installation or any other type) are derived from official EU compliance data, as published in the 'European Independent Transaction Log' (EUTL, 2013). The remaining data is collected from annual surveys of German firms in the EU ETS. Tables 1 and 2 comprise the data description and summary statistics.

The panel covers three years (2010 to 2012). Responsible managers of all EU ETS regulated companies in Germany received an online questionnaire annually in March, at a time when companies usually need to submit their compliance documents. These managers were the contact persons at the installation level, as documented in the German ETS registry. In case a company was operating more than one installation, the responsible manager of the largest installation (in terms of annual emissions) was contacted. The survey included questions about the company's main activity (economic sector based on NACE) and, in addition, discrete categories regarding the number of employees.

Every manager was asked to provide an estimation of the labour days per annum that have been spent on different categories of EU ETS related activities which might have caused transaction costs (MRV obligation, trading, general information gathering, and legal costs). Additional costs for external services related to the different activities could be reported separately, similar to the methodology applied by Ofei-Mensah and Bennett (2013) (for details on the questionnaire see 
Appendix A1). The reported days, which were spent on management obligations related to the EU ETS, were transformed into the equivalent euro value by applying hourly wages on average for 2012.These wages differed not only between the 16 German federal states (Länder) but also between the energy sector and the producing industry sector, as reported by the German Statistical Office. ${ }^{4}$ It was assumed that a work day comprised eight hours. All costs were inflation-adjusted to the price level of 2012. The total MRV transaction costs (variable tcMRV) comprised labour costs and the costs of external services reported for MRV activities.

The definition of the variable $t c M R V$ is motivated by the requirements of the MRV process. This process consists of three steps as described in the following. Firstly, installations need to monitor emissions over time. This frequently occurs by documenting fuel consumption, i.e. in the case of combustion installations. Monitoring procedures differ depending on the type of installations. There are comprehensive guidelines provided by the German emissions trading authority (DEHSt) in which requirements and procedures are specified. Secondly, the amount of emissions needs to be annually reported until the end of March. Reporting is organised via an onlineplatform. In addition to (internal) monitoring and reporting obligations, a mandatory external verification of reported emissions is required. The reported figures need to be approved by accredited third-party consultants before the official MRV process is completed. In some cases, companies need to undergo an additional review process of the DEHSt. While monitoring and reporting principally cause internal costs (i.e. labour costs), verification causes external costs (see also Mundaca et al., 2013, p. 503). Therefore, the questionnaire provided different sections in which labour input and external costs could be separately reported (see Appendix A1). External consultancy costs are also mentioned as an essential cost category by Jaraite et al. (2010, p. 199). ${ }^{5}$ The term 'administrative transaction costs' will exclusively refer to the abovementioned transaction costs for MRV in the following.

Overall, $15 \%$ of German companies regulated by the EU ETS are covered by the survey over the course of all three years. Table 1 comprises details on the data structure. Official compliance data

\footnotetext{
${ }^{4}$ Source: Statistische Ämter des Bundes und der Länder, 'Verdienste, Arbeitskosten - Nettoarbeitskosten je geleistete Stunde im Jahr 2012 im Produzierenden Gewerbe und im Dienstleistungsbereich. http://www.statistikportal.de/Statistik-Portal/de_jb22_ake02.asp (accessed 6 May 2015).

${ }^{5}$ It is possible that other additional types of costs are relevant in the MRV process, for instance, costs attributable to such expenditures as office equipment, electronic devices, software and so on. As these types of costs will only be partly attributable to the MRV process and since the share of the costs attributable to the MRV process is difficult to estimate, we distance ourselves from these type of 'overhead costs' and focus on the most important cost components.
} 
and survey data are merged on the basis of a unique firm identification number. As official compliance data are reported at the installation level and firm survey data are collected at the company level, compliance data are aggregated to the firm level. In total, a number of 237 observations (154 firms) are available. In order to rectify a potential bias of the sample towards 'large firms', weights which also take the non-response bias into account are applied (see Appendix A2).

\section{[Table 1 about here]}

Figure 1 shows a scatterplot of the (unweighted) natural logarithm (log) of annual verified emissions (logverem) and the natural logarithm of annual MRV transaction costs (logtcMRV). A linear model fit with a 95 per cent confidence interval was added. The figure suggests a positive correlation between verified emissions and MRV transaction costs. Moreover, it indicates that there are considerable fixed costs for compliance which is in accordance with the findings of Jaraite et al. (2010).

The median of total MRV costs per year for all firms in the sample amounts to 7.0 thousand euro (tEUR). For firms emitting less than $25.000 \mathrm{tCO}_{2}$ p.a., it amounts to $5.0 \mathrm{tEUR}$; for firms emitting 25.000 up to $100.000 \mathrm{tCO}_{2}$ p.a., it amounts to $6.3 \mathrm{tEUR}$; and for firms emitting more than $100.000 \mathrm{tCO}_{2}$ p.a., it amounts 12.5 tEUR. Thus, if the number of emissions per annum increases, the overall MRV costs increase simultaneously. The median of MRV costs per year and per unit of $\mathrm{CO}_{2}$ emissions for all firms in the sample amounts to 0.17 euro (EUR). For firms emitting less than $25.000 \mathrm{tCO}_{2}$ p.a., it amounts to $0.71 \mathrm{EUR}$; for firms emitting 25.000 up to $100.000 \mathrm{tCO}_{2}$ p.a., it amounts to $0.16 \mathrm{EUR}$; and for firms emitting more than $100.000 \mathrm{tCO}_{2}$ p.a., it amounts to 0.03 EUR. As expected, we observe a strong 'size-effect' in MRV transaction costs per unit of emissions.

\section{[Figure 1 about here]}

Figure 1: Scatterplot of the log of MRV transaction costs in euros (logtcMRV) and the log of verified annual emissions (logverem) which incorporates a fitted log-log pooled OLS model including an interval of 95 per cent confidence.

\section{[Table 2 about here]}




\subsection{Economic Background and Hypothesis}

If marginal transaction costs are non-zero, the marginal (shadow) price for emissions will be altered (Mundaca et al., 2013). Hence, transaction costs will have negative consequences for economic efficiency if marginal MRV transaction costs are dependent on a company's amount of emissions. The empirical examination of transaction costs related to MRV activities has to comprise non-zero marginal transaction costs in order to allow for a test of this hypothesis. Thus, it is assumed that function $f$ which describes MRV transaction costs is dependent on annual verified emissions $v$ of a firm. Given the parameterisation $f(v)=b_{0} v^{b_{1}}$, which can be easily transformed into a linear elasticity model for the empirical application, it is possible to test several hypotheses once the parameters are estimated. Administrative costs decrease with the amount of annual emissions if $b_{1}<0$, are independent of emissions if $b_{1}=0$, and increase with the amount of annual emissions if $b_{1}>0$. If $0<b_{1}<1$, the transaction costs of MRV increase at a lower rate than for the amount of annual emissions which would imply economies of scale in MRV activities as already indicated by the descriptive figures presented in the data description. Parameter $b_{0}>0$ is a scale parameter which represents 'fixed' MRV transaction costs that are independent of verified emissions.

The parameters of interest are estimated for different types of firms (economic sector or installation type) and for firms of various sizes (in terms of employees). For this purpose, we introduce indicator variables ('dummies') in order to differentiate between $b_{0}$. We also introduce interaction terms with the log of annual verified emissions to differentiate $b_{1}$ by firm type and size (in terms of the number of employees). Indicator variables and interaction terms are summarised in Table 2. Based on the parameter estimates, it is possible to test for statistical differences in MRV transaction costs paid by firms of different types and sizes depending on verified emissions and other control variables.

\subsection{Empirical Model}

In the following step, the coefficients $b_{0}$ and $b_{1}$ are estimated. Taking the natural logarithm on both sides of $f$ yields a standard linear elasticity model which allows for a direct estimation of the coefficients of interest.

$\log (f)=\log \left(b_{0}\right)+b_{1} \log (v)$ 
We are interested in estimating an augmented version of (1) by using a panel model which has the general form

$y_{i t}=\beta_{0}+\boldsymbol{x}_{i t} \boldsymbol{\beta}+c_{i}+u_{i t}$

$y_{i t}$ are the MRV transaction costs, $\boldsymbol{x}_{i t}$ is a set of variables which is expected to determine $y_{i t}, c_{i}$ is a firm-specific and unobserved effect that is either time fixed or random, and $u_{i t}$ is an idiosyncratic error term. If there is no correlation between $\boldsymbol{x}_{i t}$ and $c_{i}$, an estimation with random effects is the appropriate measure. The standard procedure to test whether a fixed or a random effects model has to be applied is the Hausman test. The null hypothesis is that 'no systematic difference of coefficients' exists between random and fixed effects. With a p-value of 0.68 and a Chi-square value of 6.59, the Null cannot be rejected. Therefore, a random effects model is chosen.

Random effects models require the assumptions of strict exogeneity and orthogonality of the unobserved effect and the explanatory variables. The variance matrix must be of full rank with variance $E\left(u_{i t}^{2}\right)=\sigma_{u}^{2}$ for $t=1, \ldots, t$ and serially uncorrelated idiosyncratic errors. Thus, random effects require the conditional variances and covariances to be zero, and a homoscedastic structure of the variance of the unobserved effect is needed (Wooldridge 2002, Chapter 10.4). As visual and numerical tests on homoscedasticity of the composite error $c_{i}+u_{i t}$ indicate that it is likely to have a heteroscedastic pattern in the data, robust standard errors are used. To avoid serial correlation in the error terms, time dummies are added to model specifications (3) in Table 3 to test for time trends, as suggested by Wooldridge (2002, p. 261).

As we are interested in estimating the effect of differing levels of annual emissions on MRV transaction costs, we specify a linear elasticity panel model of the form

$\log (c)_{i t}=\beta_{0}+\beta_{1} \log (v)_{i t}+\boldsymbol{\beta} \boldsymbol{d}_{i t}+c_{i}+u_{i t}$

The model contains verified emissions $\log (v)_{i t}$ as an independent variable along with a matrix of dummy variables and interaction terms $\boldsymbol{d}_{i t}$ which contains further firm characteristics, as reported in Table 2 (data description) and Table 3 (estimation results). 


\section{Estimation and Results}

Estimation results are reported in Table 3. The log of MRV transaction costs per year (logtcMRV) is the dependent variable. Independent variables are the log of verified annual emissions (logverem), indicator variables for small companies (1-249 employees) (dsma), for medium sized companies (250-1000 employees) (dmed), and for combustion installations (dcomb), for the allocation factor (aldifactor), and for the number of ETS installations operated by a company (instnr). Additional indicator variables for economic sectors are included (dutility, dglas, dpaper, dchemic). Indicator variables for the years 2011 and 2012 are denoted as 11.year and 12.year. Interaction terms between indicator variables and the log of annual verified emissions are denoted as [variable]_logver. The following interpretation of results is based on Column (1) in Table 3. However, the results are robust for all of the reported model specifications.

\section{[Table 3 about here]}

\subsection{Fixed Transaction Costs}

Differences in the level of 'fixed' transaction costs for MRV activities (viz. the costs which are independent of the amount of annual emissions) are identified by indicator variables and a constant. In this respect, the most important results are the observed effects for small companies (1 to 249 employees, variable dsma) and utility companies (variable dutility). Small companies face larger fixed MRV transaction costs when compared to other types of companies, whereas utility companies face lower fixed MRV transaction costs. Sector indicator variables for glass production, paper production, the chemical industry, and for combustion installations are not statistically different from zero. There are no significant effects for medium sized companies (250 to 1000 employees) when compared to the reference category 'large firms' (more than 1000 employees).

\subsection{Marginal Transaction Costs}

The positive coefficient of the variable 'log of annual verified emissions' (logverem) in Table 3 indicates that MRV transaction costs are positively correlated with the amount of annual emissions, as expected. The coefficient is greater than zero and smaller than one (p-value: 0.01). This implies that there are economies of scale in the MRV process because the observed MRV transaction costs increase at a lower rate than emissions. Therefore, MRV transaction costs per 
unit of emissions are lower for companies with a large amount of annual emissions when compared to companies with a small amount of emissions.

In order to determine if the marginal effect of annual emissions on MRV transaction costs is contingent on a company's size and type, joint parameter tests of indicator variables and the interaction terms are required. The marginal effect of annual verified emissions on MRV transaction costs is different for small companies (1-249 employees) when compared to other types of companies. The joint marginal effect (logverem + dsma_logver) is not statistically different from zero (p-value: 0.70) which indicates zero marginal MRV transaction costs for small companies. Interaction terms of the log of annual verified emissions and medium sized companies (dmed_logver) as well as combustion installations (dcomb_logver) do not show any statistically significant effect.

\subsection{Average Transaction Costs}

The combination of large fixed costs and non-zero marginal MRV transaction costs for companies with more than 249 employees also leads to pronounced differences in average MRV transaction costs, as predicted by model (1) in Table $3 .{ }^{6}$ For instance, consider a non-utility company with more than 249 employees. For a company with about 25,000 $\mathrm{tCO}_{2}$ emissions per year, average MRV transaction costs amount to 0.47 euro per $\mathrm{tCO}_{2}$. For a company with about $100,000 \mathrm{tCO}_{2}$ emissions per year, average costs amount to 0.14 euro per $\mathrm{tCO}_{2}$. At the level of $1,000,000 \mathrm{tCO}_{2}$ emissions per year, average costs amount to 0.05 euro per $\mathrm{tCO}_{2}$.

Costs are lower for utility companies. MRV transaction costs amount to 0.23 euro per $\mathrm{tCO}_{2}$ for a company with approximately 25,000 $\mathrm{tCO}_{2}$ emissions per year, 0.07 euro per tCO2 for a company with approximately $100,000 \mathrm{tCO}_{2}$ emissions per year, and 0.02 euro per $\mathrm{tCO}_{2}$ emissions for a company with approximately $1,000,000 \mathrm{tCO}_{2}$ emissions per year. Thus, although there are effects related to the 'type' of company (viz. the type of economic activity), there are also important effects related to the 'size' of a company in terms of the annual amount of $\mathrm{CO}_{2}$ emissions. In accordance with the descriptive statistics presented in the data description and previous work by

\footnotetext{
${ }^{6}$ The average MRV transaction costs presented in this section are derived from a prediction of estimation (1) in Table 3. The figures are different from those presented in the data description because figures in the data description are median values covering the whole sample without any differentiation by company type.
} 
Jaraite et al. (2010), average MRV transaction costs are higher for companies with small amounts of annual emissions when compared to companies with larger amounts of annual emissions.

\subsection{Robustness of Results}

Four regressions are reported in Table 3. Column (1) reports a weighted maximum likelihood random effects regressionwith jackknife standard errors. Weihts are applied to correct a potential bias towards larger firms in the sample. Column (2) reports a random effects regression with robust standard errors and additional interaction terms. Column (3) reports a random effects regression with additional year indicator variables in order to test for potential time trends in the data. Column (4) reports a random effects regression where the largest $1 \%$ of companies (in terms of annual emission) is omitted from the sample as an additional robustness check.

Regression (1) includes weights to account for a potential bias towards larger companies in the survey. The coefficients of main interest (variable logverem), firm-size indicator variables, and interaction terms (if significant) are slightly lower when compared to the non-weighted regressions (2) and (3), and larger when compared to regression (4) which omits the largest companies. This implies that weighting is essential in order to avoid a potential bias of results. The insignificant interaction term between the indicator variable for utility companies and the log of verified emissions (dutil_logver) in regression (2) questions the hypothesis that marginal MRV transaction costs differ for utility companies when compared to other sectors. The insignificant year indicator variables (11.year, 12.year) in regression (3) imply that there are no time trends in MRV transaction costs after inflation adjustment.

\subsection{Limitations}

As the paper uses self-reported data on MRV transaction costs, there is some ambiguity regarding the accurateness of the reported costs. The limited number of available observations and the presence of time-invariant variables (e.g. sector or firm size) impose further limitations with respect to model choice and estimation. However, the effects of main interest are highly robust throughout various model specifications. These effects are (1) the positive correlation of annual verified emissions and MRV transaction costs for 'larger' companies (more than 249 employees), (2) the differences in 'fixed' MRV transaction costs for small companies (1-249 employees) as well as for utility vs. non-utility companies, and (3) zero marginal MRV transaction costs for 
small companies. It is possible that additional effects could have been observed if a richer dataset had been available. Examples are a possible non-linear pattern in MRV transaction costs or more detailed effects with respect to firm size and type in connection with 'fixed', marginal, and average MRV transaction costs.

\section{Conclusion and Policy Implications}

The empirical picture sketched above has four important implications. Firstly, MRV transaction costs are positively correlated with the amount of annual emissions of larger companies (more than 249 employees). This implies that marginal MRV transaction costs are non-zero with possible negative consequences for economic efficiency, as already discussed in literature (Mundaca et al., 2013). Secondly, the result implies that there are economies of scale in the MRV process. The estimated coefficient of the independent variable 'log of annual verified emissions' (logverem) is significantly larger than zero but also significantly lower than one (p-value: 0.01 ).

Thirdly, 'fixed' MRV transaction costs are lower for utility companies when compared to other companies. A possible reason for this finding is that MRV procedures are highly standardised in utility companies and that the monitoring of emissions is less expensive since it is based on the carbon content of the burned fuels. Finally, MRV transaction costs are not dependent on the amount of annual emissions for small companies (less than 250 employees). However, small companies report large 'fixed' transaction costs when compared to other companies. Significant differences in average MRV transaction costs represent a cost-disadvantage for smaller companies or companies with a smaller amount of annual verified emissions when compared to larger firms.

For instance, MRV transaction costs amount to approximately 0.47 euro per $\mathrm{tCO}_{2}$ for a nonutility company with more than 249 employees and annual emissions of about 25,000 $\mathrm{tCO}_{2}$ (see Section 4.3). Assuming an EU allowance price of 7 euros, MRV transaction costs amount to approximately $7 \%$ of the allowance price, as observed in the first half year of 2015. The situation is entirely different if a company with a large amount of annual emissions is considered. A company with annual emissions of approximately 1,000,000 $\mathrm{tCO}_{2}$ faces MRV transaction costs of 0.05 euro per $\mathrm{tCO}_{2}$. This is less than $1 \%$ of the allowance price. Thus, there are important differences in MRV transaction costs with respect to the annual amount of emissions. MRV transaction costs per unit of emissions are large for companies with smaller amounts of annual 
emissions due to the existence of large fixed costs. This implies that the overall burden of MRV transaction costs could have been effectively decreased if small emitters had been excluded from the direct regulation under the EU ETS.

Overall, the results indicate that there are important 'size' and 'technology' effects which are correlated with MRV transaction costs in the EU ETS. While there is some empirical evidence for 'size' effects in the empirical literature (Jaraite et al., 2010), there is no consideration for 'technology' effects so far to our best knowledge. The findings have important policy implications as MRV transaction costs are relevant for policy design in the light of administrative efficiency. This aspect has also been acknowledged by the European Commission in directive 2009/29/EC, paragraph 11.

A possible solution to the problem of large average burdens by MRV transaction costs for smaller companies would be the exclusion (or opt-out) of these. This, however, would undermine the effectiveness of the ETS as less sources of greenhouse gas emissions would be covered by the system after an opt-out of small companies. Thus, an out-out provision can be expected to increase administrative efficiency by reducing average MRV transaction costs. However, this will occur at the expense of a decreased coverage of polluters and a potential decrease in economic efficiency. ${ }^{7}$ Thus, MRV transaction costs play an important role for policy design among other aspects. ${ }^{8}$ This represents a trade-off between broad coverage of emissions and the avoidance of large MRV transaction costs per unit of emissions for some regulated companies.

A possible way to decrease transaction cost burdens while preserving effectiveness and broad coverage of regulation would be a strict 'upstream' policy design (Joas \& Flachsland, 2014; Kerr \& Duscha, 2015). In the EU ETS, regulation takes place at the installation level in an 'end of the pipe' manner. This makes the inclusion of small installations necessary. Under upstream regulation (as interpreted here), the carbon content of intermediate products (e.g. fossil fuels) is 'priced' by the upstream regulation system in the moment the products are put on the market (Kerr \& Duscha, 2015). In this case, greenhouse gas emissions are 'priced' at the source and not at the level of final (commercial) consumers. In this situation, the overall prices of carbonintensive intermediate products incorporate the carbon price in case the products are resold. Such

\footnotetext{
${ }^{7}$ Efficiency could decrease if low-cost abatement options existed in companies which are opted-out or excluded from regulation.
} 
an approach is applicable to the energy sector and has been included in the design of the Australian carbon pricing scheme (Jotzo, 2012) which was repealed in July 2014.

Under upstream regulation, many businesses would not need to be actively covered by cap-andtrade, i.e. in cases when fossil fuels are purchased to fuel small or medium sized combustion installations. These companies would not be required to carry out MRV activities which would reduce overall transaction costs. Such a design could help to increase the administrative efficiency of climate policy and would offer the option of a broader indirect coverage of polluters, e.g. small businesses or additional sectors such as transportation.

\section{References:}

Ellerman, D. A., Convery, F. J., \& De Pertuis, C. (2010). Pricing Carbon - The European Union Emissions Trading Scheme. Cambridge: Cambridge University Press.

EUTL. (2013). European Union Transaction Log. EU ETS Allocation and Compliance Data. Retrieved from http://ec.europa.eu/environment/ets/

Hahn, R. W., \& Stavins, R. N. (2011). The Effect of Allowance Allocations on Cap-and-Trade System Performance. Journal of Law and Economics, 54(4), 267-294.

Hepburn, C. (2006). Regulation by Prices, Quantities, or Both: A Review of Instrument Choice. Oxford Review of Economic Policy, 22(2), 226-247. doi:10.1093/oxrep/grj014

Jaraite, J., Convery, F., \& Di Maria, C. (2010). Transaction costs for firms in the EU ETS: Lessons from Ireland. Climate Policy, 10(2), 190-215.

Jaraitė-Kažukauskė, J., \& Kažukauskas, A. (2014). Do Transaction Costs Influence Firm Trading Behaviour in the European Emissions Trading System? Environmental and Resource Economics, (published online: 9 October 2014). doi:10.1007/s10640-014-9831-7

Joas, F., \& Flachsland, C. (2014). The (ir)relevance of transaction costs in climate policy instrument choice: an analysis of the EU and the US. Climate Policy, (published online: 1 December 2014). doi:10.1080/14693062.2014.968762

Jotzo, F. (2012). Australia’s carbon price. Nature Climate Change, 2(7), 475-476.

Kampas, A., \& White, B. E. N. (2004). Administrative Costs and Instrument Choice for Stochastic Non-point Source Pollutants. Environmental and Resource Economics, 27, 109133. 
Kerr, S., \& Duscha, V. (2015). Going to the Source: Using an Upstream Point of Regulation for Energy in a National Chinese Emissions Trading System. Energy \& Environment.

Montgomery, W. D. (1972). Markets in Licenses and Efficient Pollution Control Programs. Journal of Economic Theory, 5, 395-418.

Mundaca, L., Mansoz, M., Neij, L., \& Timilsina, G. (2013). Transaction costs analysis of low carbon technologies. Climate Policy, 13(4), 490-513.

Ofei-Mensah, A., \& Bennett, J. (2013). Transaction costs of alternative greenhouse gas policies in the Australian transport energy sector. Ecological Economics, 88, 214-221.

Schleich, J., \& Betz, R. (2004). EU Emissions Trading and Transaction Costs for Small and Medium Sized Companies. Intereconomics, 39(3), 121-123.

Stavins, R. N. (1995). Transaction Costs and Tradeable Permits. Journal of Environmental Economics and Management, 29(2), 133-148.

Wooldridge, J. M. (2002). Econometric Analysis of Cross Section and Panel Data. MIT Press. 


\section{Appendix A1: Questionnaire (wave of March 2012, translation)}

The participants had the opportunity to choose one of the displayed options per question, except in the case of the question on administrative costs, where the survey participants were asked to type in the workdays per year and costs in EUR per year or alternatively to choose the "unknown" option. Each question offered the option "unknown" for those cases in which the survey participants were unable or unwilling to respond.

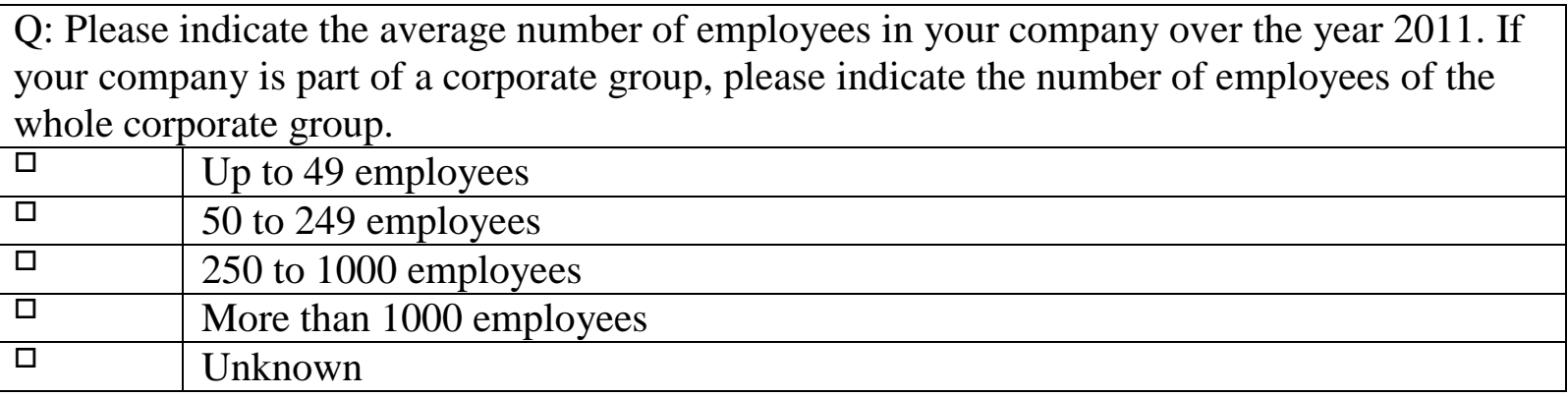

\begin{tabular}{|c|c|}
\hline \multicolumn{2}{|c|}{$\begin{array}{l}\text { Q: In which branch of the economy is your company predominantly active? } \\
\text { the most important product group that is directly or indirectly regulated by th } \\
\text { Trading Scheme }\end{array}$} \\
\hline$\square$ & Energy and/or heat generation (e.g. utility company) \\
\hline 口 & Food products, beverages, or animal feeds \\
\hline$\square$ & Textiles, wearing apparel, leather and related products \\
\hline $\bar{\square}$ & Paper and paper products, printing \\
\hline$\square$ & Coke and refined petroleum products \\
\hline$\square$ & Chemicals and chemical products \\
\hline$\square$ & Rubber and plastic products \\
\hline $\bar{\square}$ & Glass, glass products, ceramic, lime and plaster \\
\hline$\square$ & Basic metals (iron and steel, non-ferrous metals etc.) \\
\hline$\square$ & Fabricated metal products \\
\hline 口 & Machinery \\
\hline$\square$ & Motor vehicles and component suppliers \\
\hline$\square$ & Computer, electronic, and optical products. Electrical equipment \\
\hline$\square$ & Others \\
\hline$\square$ & Unknown \\
\hline
\end{tabular}

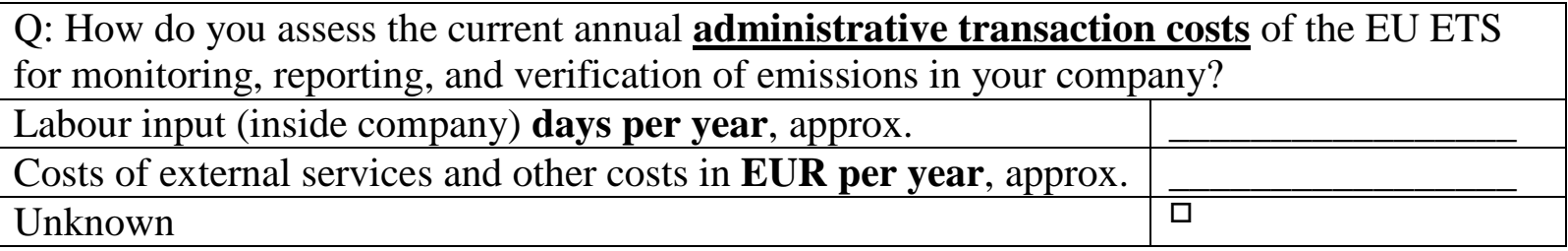


Transaction costs have been assessed in the same manner as MRV costs for the additional categories of "transaction costs for trading”, and "information costs." An additional option "no such costs" and an option to indicate that the surveyed person cannot answer the question has been provided in order to ensure that different types of transaction costs can be distinguished and that all relevant information on transaction costs are gathered.

\section{Appendix A2: Calculation of Weights}

To avoid biased results due to a domination of large firms in the regression, weights are applied. Weights are calculated on the basis of the ex-ante probability that firm $i$ will participate in the survey $P\left(s_{i}=1\right)$. Given $N$ firms in the population, this probability is defined by $P\left(s_{i}=1\right)=$ $1 / N$. A second component is related to the self-selection of firms that actually participate in the survey. Thus, the probability of participation $P\left(r_{i}=1 \mid s_{i}=1\right)$ is estimated by using a probit model that encompasses the dependent variables 'log of verified emissions' (logverem) and the activity types, as reported in the official compliance data. Weights are described by $w_{i}=$ $1 / P\left(s_{i}=1\right) \times P\left(r_{i}=1 \mid s_{i}=1\right)$. 
Table 1: Total of ETS regulated companies in Germany and coverage by the survey.

\begin{tabular}{lllll} 
& $\mathbf{2 0 1 0}$ & $\mathbf{2 0 1 1}$ & $\mathbf{2 0 1 2}$ & Overall \\
\hline Overall Germany & & & & \\
Number of Companies & 952 & 977 & 977 & 977 \\
Number of Installations & 2077 & 1990 & 1826 & \\
CO2 Emissions (MtCO2) & 428 & 454 & 450 & \\
CO2 Emissions (Median, TtCO2) & 23.1 & 25.7 & 22.4 & \\
Sample & & & & \\
\hline Number of Companies & 65 & 76 & 98 & $154^{*}$ \\
Number of Installations & 144 & 238 & 285 & \\
CO2 Emissions (MtCO2) & 111 & 51.2 & 231 & \\
CO2 Emissions (Median, TtCO2) & 31.5 & 35.9 & 43.0 & \\
& & & & \\
Sample Share & & & & \\
\hline Number of Companies & $7 \%$ & $8 \%$ & $10 \%$ & \\
Number of Installations & $7 \%$ & $12 \%$ & $16 \%$ & \\
CO2-Emissions (MtCO2) & $26 \%$ & $11 \%$ & $51 \%$ &
\end{tabular}

* The number of companies is not equal to the sum calculated over the years since many companies are covered in more than one year. 
Table 2: Sample description and summary statistics

\begin{tabular}{llcc} 
Variable & Variable description & Mean & St. dev. \\
\hline tcMRV & MRV transaction costs for compliance in EUR per year & $61,075.71$ & $264,630.43$ \\
logtcMRV & Natural logarithm of tcMRV (dependent variable) & 9.09 & 1.33 \\
verem & Verified emissions as reported in the official registry of & $1,646,285.39$ & $10,886,794.59$ \\
& the European Union (EU Independent Transaction Log) & & 2.32 \\
logverem & Natural logarithm of verem & 10.79 & 0.49 \\
dsma & $=1$ if company is a small company (less or equal 249 & 0.41 & 5.28 \\
& employees) & 4.24 & 0.47 \\
dsma_logver & Interaction term of dsma and logverem & 0.31 & 5.18 \\
dmed & $=1$ if company is a medium sized company (250-1000 & 159.76 \\
& employees) & 3.40 & 229.31 \\
dmed_logver & Interaction term of dmed and logverem & 13.11 & 6.00 \\
aldifactor & Allocation factor (number of received free allowances & 36.25 & 103.66 \\
aldifa_logver & relative to verified emissions) & 2.79 & 0.46 \\
instnr & Interaction term aldifactor and logverem & & 5.33 \\
& Number of EU ETS regulated installations operated by & 37.62 & 0.50 \\
instnr_logver & company & Interaction term instnr and logverem & 0.69 \\
dcomb & $=1$ if most installations are combustion installations & 7.47 & 5.82 \\
dcomb_logver & Interaction term dcomb and logverem & 0.43 & 0.37 \\
dutility & $=1$ if company is a utility company & 4.83 & 0.32 \\
dutil_logver & Interaction term of dutility and logverem & 0.17 & 0.26 \\
dglas & $=1$ if company produces glass products & 0.12 & 0.47 \\
dpaper & $=1$ if company produces paper products & 0.07 & 0.49 \\
dchemic & $=1$ if company produces chemical products & 0.41 & \\
11.year & $=1$ if year 2011 & &
\end{tabular}

Overall number of observations $n=237$ for 154 companies 
Table 3: Estimation results (dependent variable: log of annual MRV transaction costs, variable logtcMRV)

\begin{tabular}{|c|c|c|c|c|}
\hline Variables & $\begin{array}{c}(1) \\
\operatorname{logtcMRV}\end{array}$ & $\begin{array}{c}(2) \\
\operatorname{logtcMRV}\end{array}$ & $\begin{array}{c}(3) \\
\log \mathrm{MRV}\end{array}$ & $\begin{array}{c}(4) \\
\operatorname{logtcMRV}\end{array}$ \\
\hline logverem & $\begin{array}{c}0.308^{* *} \\
(0.140)\end{array}$ & $\begin{array}{c}0.422 * * * \\
(0.122)\end{array}$ & $\begin{array}{c}0.448^{* * *} \\
(0.109)\end{array}$ & $\begin{array}{c}0.281^{* * *} \\
(0.105)\end{array}$ \\
\hline dsma & $\begin{array}{c}2.969 * * \\
(1.358)\end{array}$ & $\begin{array}{c}4.985 * * * \\
(1.194)\end{array}$ & $\begin{array}{c}5.183^{* * *} \\
(1.287)\end{array}$ & $\begin{array}{c}2.813^{* * *} \\
(0.956)\end{array}$ \\
\hline dsma_logver & $\begin{array}{c}-0.269 * * \\
(0.120)\end{array}$ & $\begin{array}{c}-0.455^{* * *} \\
(0.104)\end{array}$ & $\begin{array}{c}-0.465^{* * * *} \\
(0.109)\end{array}$ & $\begin{array}{c}-0.252 * * * \\
(0.0834)\end{array}$ \\
\hline dmed & $\begin{array}{c}2.251 \\
(1.372)\end{array}$ & $\begin{array}{c}3.319 * * * \\
(1.147)\end{array}$ & $\begin{array}{c}3.194 * * \\
(1.326)\end{array}$ & $\begin{array}{l}1.949 * \\
(1.045)\end{array}$ \\
\hline dmed_logver & $\begin{array}{l}-0.212^{*} \\
(0.122)\end{array}$ & $\begin{array}{c}-0.308 * * * \\
(0.103)\end{array}$ & $\begin{array}{c}-0.292 * * \\
(0.117)\end{array}$ & $\begin{array}{l}-0.180^{*} \\
(0.0926)\end{array}$ \\
\hline dcomb & $\begin{array}{l}-1.087 \\
(1.279)\end{array}$ & $\begin{array}{l}0.0394 \\
(1.733)\end{array}$ & & $\begin{array}{l}-1.164 \\
(1.125)\end{array}$ \\
\hline dcomb_logver & $\begin{array}{l}0.0606 \\
(0.108)\end{array}$ & $\begin{array}{c}-0.0432 \\
(0.148)\end{array}$ & & $\begin{array}{c}0.0681 \\
(0.0950)\end{array}$ \\
\hline aldifactor & $\begin{array}{l}-0.00774 \\
(0.0621)\end{array}$ & $\begin{array}{c}-0.00644 * * * \\
(0.00148)\end{array}$ & $\begin{array}{c}-0.000730 * * * \\
(0.000273)\end{array}$ & $\begin{array}{c}-0.00759 * * * \\
(0.000896)\end{array}$ \\
\hline aldifa_logver & $\begin{array}{l}0.00513 \\
(0.0123)\end{array}$ & $\begin{array}{c}0.00400^{* * *} \\
(0.00112)\end{array}$ & & $\begin{array}{c}0.00497 * * * \\
(0.000631)\end{array}$ \\
\hline instnr & $\begin{array}{l}0.0853 \\
(0.275)\end{array}$ & $\begin{array}{l}-0.0185 \\
(0.205)\end{array}$ & $\begin{array}{c}0.0193 \\
(0.0194)\end{array}$ & $\begin{array}{c}0.216 \\
(0.221)\end{array}$ \\
\hline instnr_logver & $\begin{array}{l}-0.00447 \\
(0.0171)\end{array}$ & $\begin{array}{l}0.00136 \\
(0.0120)\end{array}$ & & $\begin{array}{l}-0.0128 \\
(0.0129)\end{array}$ \\
\hline dutility & $\begin{array}{c}-0.524^{* *} \\
(0.263)\end{array}$ & $\begin{array}{l}-2.193 \\
(1.441)\end{array}$ & $\begin{array}{c}-0.775 * * \\
(0.303)\end{array}$ & $\begin{array}{c}-0.557 * * \\
(0.251)\end{array}$ \\
\hline dutil_logver & & $\begin{array}{c}0.154 \\
(0.137)\end{array}$ & & \\
\hline dglas & $\begin{array}{l}-0.229 \\
(0.519)\end{array}$ & $\begin{array}{l}-0.201 \\
(0.526)\end{array}$ & $\begin{array}{l}-0.0607 \\
(0.352)\end{array}$ & $\begin{array}{l}-0.232 \\
(0.492)\end{array}$ \\
\hline dpaper & $\begin{array}{l}-0.585 \\
(0.422)\end{array}$ & $\begin{array}{l}-0.524 \\
(0.423)\end{array}$ & $\begin{array}{l}-0.523 \\
(0.343)\end{array}$ & $\begin{array}{l}-0.610 \\
(0.386)\end{array}$ \\
\hline dchemic & $\begin{array}{l}-0.597 \\
(0.410)\end{array}$ & $\begin{array}{l}-0.587 \\
(0.423)\end{array}$ & $\begin{array}{l}-0.666^{*} \\
(0.347)\end{array}$ & $\begin{array}{l}-0.657^{*} \\
(0.387)\end{array}$ \\
\hline 11.year & & & $\begin{array}{r}-0.0497 \\
(0.165)\end{array}$ & \\
\hline 12.year & & & $\begin{array}{l}0.0466 \\
(0.148)\end{array}$ & \\
\hline Constant & $\begin{array}{c}6.313^{* * *} \\
(1.571)\end{array}$ & $\begin{array}{c}5.109 * * * \\
(1.412)\end{array}$ & $\begin{array}{c}4.609 * * * \\
(1.166)\end{array}$ & $\begin{array}{c}6.541^{* * *} \\
(1.200)\end{array}$ \\
\hline Observations & 237 & 237 & 237 & 234 \\
\hline Number of firms & 154 & 154 & 154 & 152 \\
\hline
\end{tabular}




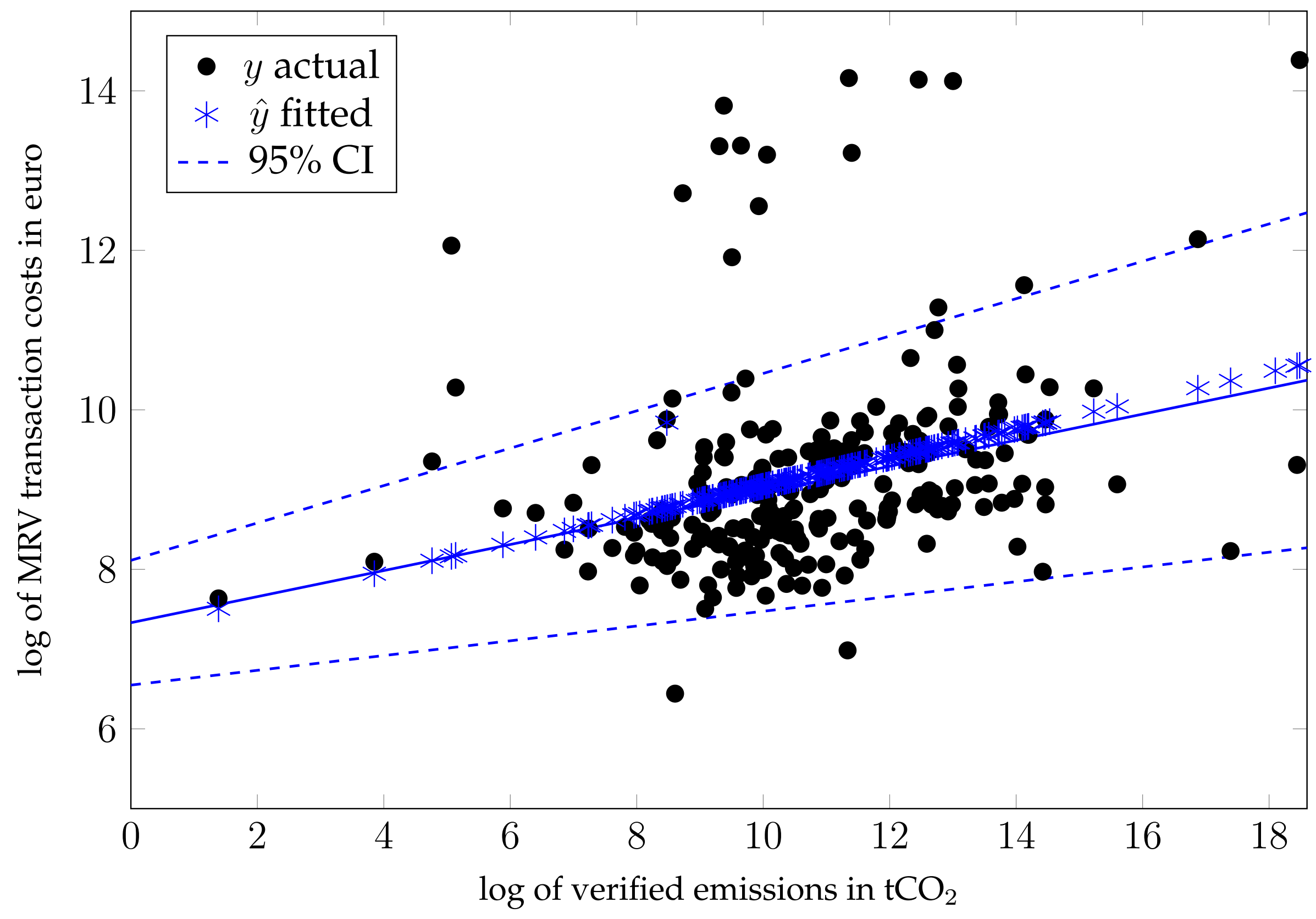

